\title{
Teresa Cabré* and Antonio Fábregas* 3rd person clitic combinations across Catalan varieties: Consequences of the nature of the dative clitic
}

https://doi.org/10.1515/tlr-2018-2010

\begin{abstract}
This article argues that variation in how 3rd person clitic combinations are solved across Catalan varieties depends on the internal morphosyntactic shape of the dative clitic in each variety. We argue that the dative clitic in Valencian Catalan is an inherently case-marked pronominal form (KP), while non Valencian Catalan varieties, that contain a locative clitic, build the dative as a definite locative pronominal which receives structural case. This allows Valencian Catalan to license each clitic in a different area, while non Valencian Catalan is forced to license a sequence of clitics in the same area, with the result that the two forms compete with each other for the licensing by the same head, leading to surface impoverishment of the sequence. Our analysis provides an explanation of these impoverishments as simple syntactic competition for licensing by the same set of heads, making OCP effects in morphology or syntax unnecessary as analytical devices for such cases.
\end{abstract}

Keywords: clitics, Catalan, clitic sequences, agreement, nominal projections

\section{Introduction}

One of the central questions in generative linguistics in the last years has been whether categories and word classes are universal or not. While previously the answer tended to be that Universal Grammar defines a set of universal categories (Chomsky 1965; with the features $\mathrm{N}$ and V that defined the main lexical classes;

Antonio Fábregas' research has been partially financed with project FFI2014-56968-C4-2-P, La variación en la interfaz sintaxis-discurso, from the Spanish Ministry of Economy. Teresa Cabré's research is funded by grants 2017 SGR 634 from AGAUR-Generalitat de Catalunya and FFI201676245-C3-1-P from the Spanish Ministry of Economy.

*Corresponding authors: Teresa Cabré, Departament de Filologia Catalana, Facultat de Lletres, Edifici B, Universitat Autònoma de Barcelona, 08193 Bellaterra (Barcelona), Spain, E-mail: Teresa.Cabre@uab.es

Antonio Fábregas, Institute of Language and Culture, HSL-Facultet, Universitet i Troms $\varnothing$-Norway’s Arctic University, N-9037 Tromsø, Norway, E-mail: antonio.fabregas@uit.no

Ә Open Access. (C) 2019 Cabré and Fábregas, published by De Gruyter. (cc)BY-NC-ND This work is licensed under the Creative Commons Attribution-NonCommercial-NoDerivatives 4.0 License. 
Hale and Keyser 2002; with a set of universal configurations), a different type of consensus has emerged in recent years whereby Universal Grammar is much more underspecified than that. This has opened the door to approaches where grammatical categories are underspecified in different ways: Wiltschko (2014) proposes that each grammatical category has a conceptual part which can vary from language to language; Ramchand and Svenonius (2014) have proposed that beyond the universal order C-T-V Universal Grammar does not specify any form of fine-grained functional sequence. As a consequence of these approaches, one possibility that was not considered previously becomes prominent:

(a) A category X might correspond to different objects in languages L and L'

One central claim of this article is that the object that, descriptively, is labeled 'dative' in Valencian Catalan is structurally different from the object that receives the same label in the Central varieties of Catalan (for instance, Barcelona Catalan). Our claim is that just because two objects receive the same name -due largely to linguistic tradition, and the use of labels based on some languages for the description of others- there is no guarantee that the two objects share the same set of properties; the properties have to be diagnosed through careful and detailed analysis of the characteristics that the object has within the language.

The goal of this article is to motivate an analysis where the different ways in which Catalan varieties treat 3rd person clitic combinations depends on how each variety defines the so-called 'dative' clitic. We will argue that if the variety contains a 'dative' clitic endowed with a KP projection, a 3rd person clitic sequence can be grammatical because the language can license the dative in a separate area that does not compete with the accusative. In contrast, if the variety defines the 'dative' clitic as a DP, the clitic sequence will be ungrammatical because that 'dative' competes for licensing with the accusative form, which is also a DP, in the same area. This procedure has the consequence that the (un)grammaticality of 3rd person clitic combinations can be treated as a syntactic phenomenon without resorting to morphological Obligatory Contour Principles (OCP) or syntactic distinctiveness constraints (Richards 2010; Nevins 2012).

The article is structured as follows: in the next section we will provide initial plausibility to the claim that objects classified as datives can have different natures across languages. In $\S 3$ we will present data from Catalan varieties which suggest a correlation between the nature of the 'dative' clitic and the availability of 3rd person clitic combinations. This will allow us to develop an analysis (§4) where we argue that the patterns can be explained without 
resorting to distinctiveness. $\S 5$ discusses additional advantages of the approach, and extends it to further cases.

\section{The problem with datives}

Among cases, datives are probably the most plausible candidate to allow an analysis where different languages define that form in distinct ways, because datives are well-known for displaying distinct behaviours in different languages and contexts.

There is a consensus that accusative and nominative are structural cases, with a defined set of properties: for instance, Chomsky's 2000 and 2001 generalisation restricting accusatives to phi complete verbal environments, or the relation between verbal agreement and nominative-marked arguments. This is not the case with datives, which appear in different configurations (Cuervo 2003): for instance, in Catalan, distinct tests diagnose a dative like (1a) as a low dative which is internal to the predicate, relating two objects; a dative like (1b) as a high dative which relates an entity with a whole state and a dative like (1c) as an even higher dative that involves some form of force and speaker-involvement in the whole situation.

(1) a. Li vaig donar un llibre a la Maria. her.dat gave a book to Maria 'I gave a book to Maria'

b. A la Maria li fan fàstic els tomàquets. to Maria her.dat give disgust the tomatoes 'The tomatos disgust María'

c. El nen no se li cura. the child not se him/her.dat heals 'The child does not heal, and that affects him/her'

It is fair to say that there is a consensus that nominative is an instance of structural -that is, structure-conditioned-case, while something like locative would be an instance of inherent case -that is, case related to meaning or to a lexical selection, and thus insensitive to the structural position-. This consensus does not extend to datives, which have been considered instances of structural case (Cuervo 2003 and the rest of the literature on applicatives) or instances of inherent case (Woolford 2006; see Gísli Jónsson 2012; for yet another complication). In relation to this, it is well-known that some languages 
allow quirky-subjects in dative (Icelandic, Zaenen et al. 1986), but this is far from being a universal property of datives. Datives that cannot act as subjects for instance in German (Bayer 2004), and there are even languages where some datives can act as subjects and others cannot (Russian, Moore and Perlmutter 2000).

More directly relevant to the purposes of this article, there are already claims in the literature that datives do not need to be defined as distinct cases within a system. In particular, Leu (2015) proposes that German datives (and genitives) are the spell out of possessive structures rather than cases on a par with nominative and accusative nominals, given their distinct syncretism patterns, the distinct morpheme ordering facts and the distinct pattern of agreement that they trigger in determiners and adjectives. This contrasts, prima facie, with what we call a dative in Spanish, where the existence of systematic patterns of syncretism with accusatives (leísmo, 2 and differential object marking, 3) suggest that they should be considered cases.

(2) a. Le di un libro a María.

her.dat gave a book to María

'I gave a book to María' (dative)

b. La vi.

her.acc saw

'I saw her' (non-leísta Spanish, accusative marking)

c. Le vi.

her.LEI saw

'I saw her' (leísta Spanish from the Basque Country, syncretic with dative)
a. (Vi) a María.
saw DOM María
b. (Le di un libro) a María.
her gave a book to María

All in all, it seems that what we call 'dative' in descriptive approaches does not correspond to one single type of element with respect to (i) the syntactic context where it appears; (ii) the possibility of acting as a derived subject and (iii) the degree of integration with the case-marking system. From a certain perspective, this is expected. Under which conditions should we expect that 'dative' is a homogeneous entity across languages? The default assumption would be that this should be the case only if Universal Grammar fully specifies a set of cases that languages draw from (as for instance Caha 2009 argues). However, this seems implausible from a conceptual perspective, because UG 
seems to be much more limited (Chomsky 2005), and from an empirical perspective, because languages do not use the same overt case marking procedures (eg., ergative languages with all their subtypes and nominativeaccusative languages). At best, choosing one case system or another should be viewed as a choice among parametric options, and then nothing guarantees that the feature endowment of a dative in language L should correspond also to a dative in language L'.

In fact, when we look at typological surveys, we find that the criterion to call some object 'dative' across languages tends to be semantic: Næss (2009) uses as her criterion that a dative must be a type of marking prototypically used to introduce goals or recipients, and immediately acknowledges that beyond this prototypical situation something identified as a 'dative' could cover also other notions, such as experiencers, affected objects, locatives, etc. Our claim is that this semantic criterion is not enough to guarantee that we identify the same type of object across languages, in the same way that the semantic criterion 'denotes additional properties of a nominal' does not allow us to identify a homogeneous class of adjectives cross-linguistically (Stassen 1997).

\section{Valencian Catalan (VC) vs. non valencian catalan (nVC) dative clitics}

This article will concentrate on the distinctions between two Catalan varieties:

(a) Valencian Catalan: a family of subvarieties spoken in the Valencian country

(b) Non-Valencian Catalan: a family of subvarieties spoken in Catalonia (including North Catalonia) and the Balearic Islands

On the surface, the singular form of the dative is identical in both varieties. Dative cliticizes as $l i$ in singular.
a. (VC) Li
donaré
el llibre
b. (nVC) Li
donaré
el llibre
him/her.dat give.fut.1s the book

However, in the plural, the two varieties already contrast in the shape of their dative clitic: 

a. (VC) Els
donaré
el llibre.
b. (nVC)
donaré
el llibre.
them.dat give.fut.1sg the book

Our claim is that this difference, and others we will get to immediately, motivate an analysis where the dative clitic in (4) corresponds to different objects in each variety, despite the surface identity. In particular, we will argue that in nVC the dative is an animate locative (Martín 2012a, 2012b). In VC this decomposition is impossible, given that the variety lacks a locative clitic /i/.

\subsection{Valencian catalan clitics}

(6) presents the set of accusative clitics in VC; these are identical to nVC. ${ }^{2}$

1 This representation is based on the orthographic form; depending on the subvarieties, the vowel is reduced ([əlzi]) or not ([əlzi]).

2 Here we will consider only accusative and dative forms; we leave aside the partitive clitic and its combinations. There are two empirical complications that prevent us from treating the partitive clitic in this article and at this point. The first one is that currently the literature lacks a precise description of how the different combinations of partitive and dative clitics (for instance, Bonet 2002 cites li'n, n'hi, ni li for the singular dative, and els en, [əlzin], [ənzi], [əlzəni], [ni], [nilizi] for the plural dative) match with the different solutions to the 3rd person clitic combinations, or with other facts about the clitic system and the contexts of use of the partitive; our own fieldwork has confirmed that the solutions are sometimes variable within what should be one single variety. The second one is that the variety of solutions is much broader than in other clitic combinations, which does not make it possible to have a detailed analysis in this same article. In short, at this moment we lack sufficient data to integrate this clitic in our analysis. An anonymous reviewer correctly points out, however, that en could be a candidate to spell out the $\mathrm{N}$ layer, and for this reason we will provide a short sketch of how en in our view spells out more material than the $\mathrm{N}$ layer itself, in order to show how it is differentiated in our approach. The clitic en (IEC 2016: § 18.6.3) appears in a number of core cases where what all substituted forms have in common is that they are introduced with the preposition de 'of'. This includes source places (i), noun complements (ii) and verb prepositional arguments (iii):

(i) De la consulta encara no n' ha sortit ningú.

of the office still not of-it has exited nobody

'Of the office, nobody has come out yet'

(ii) Qui en recordava tots els detalls eres tu.

who of-it remembere dall the details was you

'You are the one that remembered all the details (of that)'

(iii) $\mathrm{Tu}$ no en vols parlar mai.

You not of-it want speak never

'You never want to talk about it' 
(6) Accusative clitics

a. el masc.sg

b. la fem.sg

c. els masc.pl

d. les fem.pl

e. ho neuter

The accusative system is amenable to a regular morphological decomposition, as follows. Note that the neuter lacks an /1/ component, while the other forms, that are marked with gender and / or number, contain it. The plural forms are marked, regularly, by /z/ (orthographically, -s), as other plurals. The singular clitics contain the marker /a/, which becomes /e/ before the plural marker. Masculine forms are unmarked. This suggests a decomposition like (7), where we mark missing morphemes as null morphs $(\varnothing)$ for expository convenience.
(7) a. (e)1-ø
b. $1-a-\varnothing$
c. (e)l-ø-s
d. l-e-s
e. ho

The form / $/$ is present only when the entity is non-neuter, and is identical to the morpheme found in the definite article el / els / la / les 'the'. The neuter form,

This strongly suggests that en spells out not just $\mathrm{N}$, but a much more complex structure that might contain a place $\mathrm{N}$ (cf. i) but also involves some higher projections related to the preposition $d e$, used as a genitive case marker or not. When the partitive seems to substitute an indefinite noun (iv), we believe that a relevant fact is that in such cases it denotes the 'source' group from which a particular portion is selected, count or mass; naturally, the preposition de 'of' is also involved in partitive structures as a marker of the group which the specific quantity is taken from (v).
(iv) Ja n' he comprat tres.
Already of-them have.1sg bought three 'I have already bought three (of them)'
(v) Dos pams de cinta blanca
Two handspams of ribbon white
'two handspams of white ribbon'

So, in short: the difference between the partitive and other clitics is that the partitive is related to a particular prepositional marking, specifically to de 'of'. We intend to integrate the partitive clitic in the future, as we obtain more detailed data of how the different solutions correlate with further properties. 
note, corresponds to an object that cannot be pluralised and is not marked by gender overtly, but can be referential. This suggests, descriptively, a decomposition like (8).

(8) Valencian Catalan clitics ${ }^{3}$

\begin{tabular}{|l|l|l|l|}
\hline$D$ (definiteness, individuation) & Gender & Number & \\
\hline $\mathbf{( e )} \mathbf{1}$ & - & - & m.sg \\
\hline $\mathbf{l}$ & $\mathbf{a}$ & - & f.sg \\
\hline $\mathbf{( e ) 1}$ & - & $\mathbf{s}$ & m.pl \\
\hline $\mathbf{l}$ & $\mathbf{e}$ & $\mathbf{s}$ & f.pl \\
\hline \multicolumn{3}{|c|}{ ho } & neuter \\
\hline
\end{tabular}

If we move now to the dative clitics in VC, one striking fact is that the two forms are not morphophonologically related to each other, except for the presence of one segment $(/ 1 /)$.

(9) Dative clitics

a. li dative.sg

b. els dative.pl

Crucially, in this variety there is no segment /i/ in the plural dative form, which is surface identical to the plural masculine accusative els. Moreover, there is no single clitic form in VC that corresponds to this /i/ form; in other words, VC lacks a locative clitic hi. All these factors lead us to the following conclusion:

(10) In VC the form li is an undecomposable dative-marked pronoun.

In other words: while VC and $\mathrm{nVC}$ share a common historical origin where presumably the dative was built over the locative element, the loss of $h i$ in VC lead to a reinterpretation of what originally was a distinct morpheme as a phonological segment within a single exponent that spells out a pronoun marked with dative case.

With respect to the dative plural, there is some evidence that the final /z/ should not be treated as a separate plural morpheme, despite the fact that it

3 Unless otherwise noted, the decomposition reflects the orthographic form of the clitics. 
would be homophonous to the regular plural marking in this variety. The main reason not to treat /z/ as a separate plural morpheme in this variety -even though its historical origin is certainly the plural marker- is that there is a morphophonological asymmetry between the regular plural $-s$ and this segment when they appear immediately following the consonant /l/ (Todoli 1992). In sequences of clitics, the /lz/ cluster is simplified to /z/ (11).

(11) els els $\rightarrow$ /ezez/

In contrast, the segmentable plural -s does not trigger the same process:

(12) pèl-s $\rightarrow \star \star / p e z /$

hair-pl

This asymmetry suggests that the status of the final $-s$ is different in both cases; in particular, the idea is that the cluster reduction is completely blocked across a morpheme boundary. For this reason, in the analysis we will assume that els, like $l i$, should be treated as a single exponent even though the /s/ and /i/ correspond to formatives that in earlier stages of the language where independent morphemes.

To summarise, these are the facts about the clitic system of VC:

a) There is no locative clitic (nothing corresponding to hi 'loc.cl')

b) li is an undecomposable dative form

\subsection{Non Valencian Catalan (nVC) Clitics}

Compare this to the system in the non Valencian variety. The accusative forms are identical to VC (13), but in the rest of the system there are two crucial differences. First, the plural dative clitic contains the segment /i/ that the singular also contains; it appears after the plural morpheme (14). Second, there is an independent locative clitic corresponding to /i/ (15) in this variety. We claim that both facts are related.

(13) Accusative clitics
a. el
masc.sg
epenthetic $[\partial / \mathrm{e}]+1$
b. la
fem.sg
$1+$ feminine
c. els
masc.pl
epenthetic [ə/e] $+1+$ plural
d. les
fem.pl
$1+$ feminine + plural
e. ho
neuter
NO 1- 
(14) Dative clitics
a. 1-i
dative.sg
$1+\mathrm{i}$
b. (ə/e)l-z-i
dative.pl
epenthetic $[$ ə/e] $+1+$ plural $+\mathrm{i}$

(15) Locative clitic

hi loc

In comparison with the VC varieties, what is crucial here is that the existence of a locative clitic /i/ makes it possible for the speaker to analyse the dative /li/ as a morphologically complex form consisting of the locative and the definite marker /1/. In the plural, consequently, the /i/ formant is also present, following the plural marker.

This leads us to the following segmentation, where the locative is present in the dative forms, as previously argued in detail by Martín (2012a), presented in othographic form:

(16)

\begin{tabular}{|l|l|l|l|l|}
\hline $\begin{array}{l}\text { D (definiteness, } \\
\text { individuation) }\end{array}$ & Gender & Number & $\begin{array}{l}\text { Locative } \\
\text { element }\end{array}$ & \\
\hline $\mathbf{( e ) l}$ & - & - & No & m.sg \\
\hline $\mathbf{l}$ & a & - & No & f.sg \\
\hline$(\mathbf{e}) \mathbf{l}$ & - & $\mathbf{s}$ & No & m.pl \\
\hline $\mathbf{l}$ & $\mathbf{e}$ & $\mathbf{s}$ & No & f.pl \\
\hline $\mathbf{l}$ & - & - & $\mathbf{i}$ & dat.sg \\
\hline $\mathbf{( e )} \mathbf{l}$ & - & $\mathbf{s}$ & $\mathbf{i}$ & dat.pl \\
\hline- & - & - & $\mathbf{i}$ & locative \\
\hline
\end{tabular}

Note that we treat /i/ in this segmentation as a locative element -specifically a locative noun-. This differs from previous analyses, such as Rigau (1978, 1982) and Martín (2012a, 2012b). See $\S 4.1 .2$ for the comparison with these approaches and our arguments to take this analytical decision.

\subsection{Clitic combinations}

The way in which VC and nVC solve the third person clitic combinations is also different (Bonet 1991, 1993, 2002; Martín 2012a, 2012b; Mascaró 1986; Todolí 1992; Viaplana 1980; Walkow 2011). 
Valencian Catalan has two subvarieties that we want to highlight. In the first one (VC1) when a dative and an accusative clitic combine, there is no modification of the morphological exponents. Not taking into account the epenthetic vowel, which is redundant given the context, and possible morphophonological processes (such as that represented in (17) in which the $l z$ sequence is reduced to /z/), the dative and the accusative clitics preserve their forms.

\begin{tabular}{|ll|l|l|}
\hline VC1 & & Dative.sg li & Dative.pl els \\
\hline Acc.m.sg & el & li'l [lil] & els el [e(l)zel] \\
\hline Acc.f.sg & la & li la [lila] & els la [e(l)zla] \\
\hline Acc.m.pl & els & li'ls [li(l)s] & els els [e(l)ze(l)s] \\
\hline Acc.f.pl & les & li les [liles] & els les [e(l)zles] \\
\hline
\end{tabular}

Note that in this subvariety the clitic sequence can duplicate the information present in the cluster. As a form like (18) illustrates, the distinctions between masculine / feminine in the accusative clitic and the distinction between plural / singular in both clitics are preserved in the cluster for at least the accusative clitic. There is also two /l/ forms in the sequence.

(18) els les

D,pl. D, f., pl.

In the second variety of VC, which we will call VC2, in contrast, there is surface impoverishment of the accusative, which becomes surface identical to a neuter. However, inside the clitic, the form $h o^{4}$ can combine with a plural marker, something that is impossible when ho appears outside a clitic sequence -as expected due to its neuter nature-.

\begin{tabular}{|ll|l|l|}
\hline VC2 & & Dative.sg li & Dative.pl els \\
\hline Acc.m.sg & el & li ho [liw] & els ho [e(l)zo] \\
\hline Acc.f.sg & la & li ho [liw] & els ho [e(l)zo] \\
\hline Acc.m.pl & els & li ho-s [liwz] & els ho [e(l)zo] \\
\hline Acc.f.pl & les & li ho-s [liwz] & els ho [e(l)zo] \\
\hline
\end{tabular}

4 In VC, the neuter is generally pronounced as /o/, but in combination with the dative /li/, it becomes $/ \mathrm{w} /$. In what follows, we assume that this is the result of a morphophonological process and treat it as two allomorphs of the same exponent. 
Finally, let us consider now the non Valencian Catalan clitic combinations. In $\mathrm{nVC}$, the combination gives a surface form that is identical to only the dative, triggering a great deal of surface syncretism across combinations that are known to be distinct.

(20)

\begin{tabular}{|l|l|l|}
\hline nVC & Dative.sg [li] li & Dative.pl [əlzi] els hi \\
\hline Acc.m.sg el & [li] l'hi & [əlzi] els hi \\
\hline Acc.f.sg la & [li] l'hi & [əlzi] els $h i$ \\
\hline Acc.m.pl els & [əlzi] els $h i$ & [əlzi] els $h i$ \\
\hline Acc.f.pl les & [əlzi] els $h i$ & [əlzi] els hi \\
\hline
\end{tabular}

Note that the system has a lot of surface syncretism. Only two forms are used in the dative + accusative combinations: if both forms are singular, [li] emerges. However, as soon as one of the two forms, accusative or dative, is plural, the form used is [əlzi]. If both forms are plural, only one plural marker appears; only one / 1 appears, and, just as in the dative, the clitic combinations do not express gender motion. With a certain degree of variation, this paradigm is the most frequent in $\mathrm{nVC}$.

\section{The analysis: Competition for licensing in the middle field}

Let us now move to the analysis, and let us start by presenting our main claims in a summarised fashion.

(a) Arguments are licensed as grammatical complements of verbs in a designated area between T and V (the clitic area, Sportiche 1996).

(b) Languages which differentiate through case marking dative and accusative clitics can (but do not have to) duplicate the clitic area, with one area to license dative clitics and another area for accusative clitics

(c) If the language does not assign distinct case marking to accusative and 'dative' clitics, both clitics compete for licensing in the same area

(d) When there is competition, the result is a clitic cluster which has undergone surface impoverishment because there is only structural space to license one number, one gender, one $\mathrm{D}$ and one $\mathrm{N}$ 
This section is structured as follows. We will first present our assumptions about the ordering of heads within a pronoun, we will motivate the claim that /i/ in nVC is not a case marker, and make our assumptions about case explicit. With this background, in $\S 4.2$ we will proceed to an analysis of the structural and morphological material associated to each clitic, and we will use this to explain the distinct clitic sequences in each case.

\subsection{Background}

\subsubsection{The internal structure of pronouns}

The standard assumptions about the order of projections within the (pro)nominal domain are represented in (21). Within the higher functional layers of pronouns, the hierarchical order is $\mathrm{K}$ (case), D(determiner), Num(number) and, for those that divide it, Gen(gender) (cf. Neeleman and Weerman 1999; Cinque 2005; Picallo 2006; Wiltschko 2014; among many others). There is in addition a debate with respect to whether pronouns contain (possibly empty) N(noun) projections or not (Panagiotidis 2002; Déchaine and Wiltschko 2002). In what follows we will assume that clitic pronouns are full projections of lexical NPs, and therefore that they have a $\mathrm{N}$ layer at its root, which is spelled out as $\emptyset$.

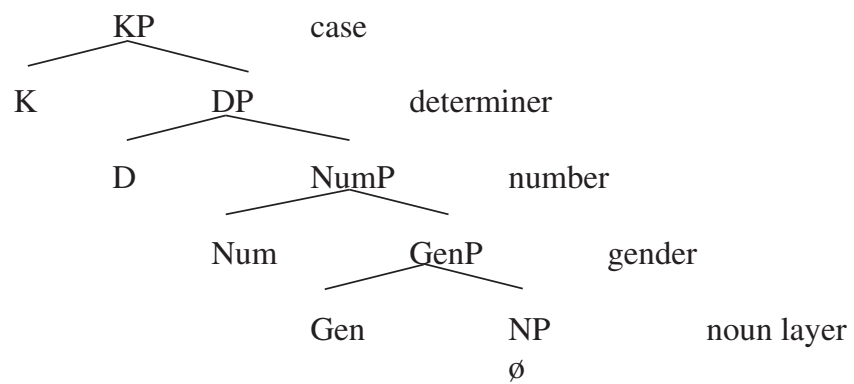

Let us assume that this rough set of projections are universally ordered due to the cognitive principles that Wiltschko (2014) propose: the N layer has a classifying function, determining the range of individuals which the pronoun can refer to (humans, regions of space, etc.). Number (and possibly gender) incorporates the viewpoint adopted with respect to those individuals (groups, singular entities, etc.). Determiners have an anchoring function and incorporate notions such as givenness. Finally, the case layer acts as a linker to the external structure, in this case to the predicate that takes the pronoun as its argument. 


\subsubsection{The nature of $h i$ as a place noun}

Our claim that /i/ spells out a place $\mathrm{N}$ needs to be further substantiated, particularly due to the fact that there are at least two alternative analyses in the market: Rigau $(1978,1982)$ treats $h i$ as a pronoun that marks dative case in inanimate objects, while Martín (2012a, 2012b) -following other cases discussed in Kayne (2008) - treats it as a deictic element that can modify a silent place nominal. Let us see now why we do not follow these analyses, and what are the independent reasons to propose that /i/ is the spell out of the silent nominal itself.

First, let us see some reasons why it is not plausible to consider /i/ a case marker. The order of projections and the position occupied by $-i$ is one reason not to associate /i/ to case. Why is not the plural dative form *ils? The /i/ could be treated as case only on the assumption that the DP moves higher than KP, so that /i/ is final in the dative forms (22).
a. (ə)lzi
b. [K -i [D l- [Num z [Gen $\varnothing[\mathrm{N} \varnothing]]]]$
c. [KP [D 1 [Num z...]] -i [D]- [Num-z [Gen $\varnothing[\mathrm{N} \varnothing]+]]$

It is unclear what would motivate this movement in the syntax, which moreover would count as an infraction of antilocality (Abels 2003). There are no plausible phonological reasons for this movement, also: in fact, before movement the sequence would be /ilz/, which avoids the need to introduce an epenthetic vowel at the beginning, as in /əlzi/. In contrast, if /i/ is spelled out in $\mathrm{N}$, no movement operation is needed to derive the attested order.

Second, saying that $-i$ corresponds to case misses a generalisation: in the dative there is no gender motion in these varieties. If /i/ is in KP, it is unclear why $\mathrm{K}$ would force GenP to have no specific value for gender. However, if /i/ is treated as an $\mathrm{N}$ form, the fact that datives lack gender motion follows: the $\mathrm{N}$ layer is always the same element, a noun corresponding roughly to PLACE. It might be that PLACE lacks any gender value, and it might be that PLACE happens to carry masculine gender: in either case, datives are expected to lack gender motion because they are built over N PLACE.

Third, if $\mathrm{N}$ is defined as the layer that determines the range of individuals of a pronominal form, the fact that /i/ is the pronominal form used to refer to regions in space motivates that it should be considered as a form of $\mathrm{N}$ (or at the very least, that it contains an $\mathrm{N}$ layer that delimits the set of entities over which it ranges). Specifically, here we will treat it as a noun that picks space entities and not other types of individuals for the denotation of the noun. 
Here we take /i/ to be a nominal element (following Kayne's 2005 idea of silent PLACE: $h i$ is an overt version of PLACE).

Given uses such as (23), the account that $h i$ is a case marker also faces different problems once one looks at the other uses of the form.

(23) A això ${ }_{i}$, hi $i_{i}$ dedico molt de temps.

to that, HI devote lot of time

'I devote lots of time to this'

One main problem for this account is that hi can substitute adjuncts, which by assumption do not get any case: particulary, manner adjuncts can be related to this form (IEC 2016: $§ 18.6 .4 .3 a)$.

(24) Ara parla assenyadament ${ }_{\mathrm{i}}$, però abans no hi $\mathrm{i}_{\mathrm{i}}$ parlava. now speaks reasonably, but before not HI spoke 'He speakłs reasonably now, but before he didn’t speak in that way'

We also part ways with Martin (2012a, 2012b), who argues that the /i/ component of the dative in $\mathrm{nVC}$ is a manifestation of DP, with (25) as the base structure.

(25) [DP hi [NP els]]

Martín (2012a, 2012b) -see also Boeckx and Martín (2013) - is then forced to assume a movement operation as in (26) to obtain the right order.

(26) $\left[\mathrm{NP}\right.$ els [DP hi [NP $\left.\left.\left.\mathrm{t}_{\mathrm{i}}\right]\right]\right]$

We see this structure problematic for the same reasons as (22): anti-locality is violated here, and moreover it is unclear how the semantic system could interpret a configuration where NP dominates DP. For these reasons, taking the linear evidence seriously, we treat /i/ in this variety as an instance of $\mathrm{N}$, specifically as a locative noun whose role is to select among a range of regions in space.

There are other arguments against treating it as a deictic element. Typically, deixis displays proximal / distal contrasts, as in French (Kayne and Pollock 2010; cf. 27).
a. celui-ci
b. celui-là dem-here 'this' dem-there 'that' 
Catalan hi lacks such contrasts, which makes it less likely that it corresponds to a deictic element. In fact, in locative adverbs the distal / proximal contrast does not necessarily involve the exclusion of /i/ as second element (28).
(28)
a. aqu-í
here
b. all-1́
there

The comparison with the demonstrative suggests that if a deictic element is involved in (29a), it is the first member, /ak/
(29) a. aqu-est
this
a. aqu-ell
that

Second, a non referential $h i$ is attested in a number of stative expressions referring to capacities and qualities of humans, such as those in (30) (IEC 2016: § 18.6.4.4):

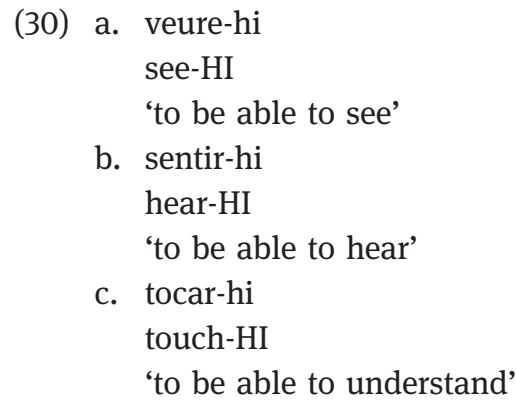

Our proposal that hi corresponds to a place nominal is able to account for a number of core independent uses of the form, among them all locative uses where it expresses the position occupied by an entity, or the final goal of a movement event (31) (IEC 2016: $§ 18.6 .4 .2 a$ )
a. A la tarda hi havia la taula rodona. in the afternoon $\mathrm{HI}$ was the table round 'In the evening there was a round table'
b. No hi podré anar.
not HI will.be-able-to go
'I won't be able to go there'

Interestingly, hi cannot refer to temporal expressions -against its deictic character- unless the time period is located explicitly within a calendar, program or time plan (32; cf. IEC 2016: § 18.6.4.3c): 
(32) a. *La setmana passada ${ }_{i} s^{\prime} h i_{i}$ van casar els meus veïns. the week past SE HI aor marry the my neighbours Intended: 'Last week, my neighbours got married'

b. $\mathrm{Hi}_{\mathrm{i}}$ sopem cada dia, a les nou $\mathrm{u}_{\mathrm{i}}$ HI dine each day, at the nine 'We have dinner each then, at nine'

The locative characterisation of $h i$ as a locative expression can treat the other cases mentioned in the literature as specific extensions of the notion 'place'. Starting with the inanimate datives mentioned by Rigau (1982), the use of surface locative is reminiscent of the cross-linguistically well-attested interpretation of inanimate recipients of an event as goals towards which an event is directed (Næss 2009), which produces contrasts such as (33) in for instance Spanish:
a. Le envié un paquete a María.
her.dat sent a package to María
'I sent a package to María'
b. Envié un paquete a Londres (=allí).
sent a package to London (=there)
'I sent a package to London'

Other cases of the use of $h i$ are comptabile with a metaphorical extension of the notion of place, understood as a general cognitive space where properties or qualities are adscribed to a subject. This is the case of the predicates in (31), where no deixis is possible and -we argue- the locative incorporates the information that the verb has to be interpreted as a state placed within the personal sphere of the subject whose properties are being described. Similarly, in (34) hi represents the property which is the goal of a change of state event interpreted as a metaphorical movement event; we are grateful to an anonymous reviewer for this example-.

(34) En Joan no era calb però amb l'edat s'hi ha anat tornant the John NEG 3s.was bold but with the-age SE-HI has gone becoming 'John wasn't bold, but with age he has become bold'

Similarly, manner adverbs -interpreted as qualities of events, as opposed to qualities of participants in the event- are replaced by hi for the same principle: the property is interpreted as a region within which the properties of the entity are defined. 
Admittedly, the most difficult cases to address in an account where $h i$ is taken as a place nominal are those illustrated in (35), where $h i$ seems to substitute a prepositional argument of the verb, typically (but not exclusively) introduced by the preposition $a m b$ 'with' (IEC 2016: § 18.6.4.1).

(35) a. Compta amb mi $\mathrm{i}_{\mathrm{i}}$, compta-hi $\mathrm{i}_{\mathrm{i}}$ sense reserves. count with me, count-Hi without reservations 'Count on me, count on me without worries'

b. Hem de contribuir a la despesa $\mathrm{i}_{\mathrm{i}}$ o no $\mathrm{hi}_{\mathrm{i}}$ hem de contribuir? must of contribute to the expense, or not HI must of contribute? 'Must we contribute to the expenses, or we must not contribute to them?'

c. Amb la Maria ${ }_{\mathrm{i}}$, hi $\mathrm{i}_{\mathrm{i}}$ parlo sovint. with the Maria, Hi speak often 'With Maria, I speak often'

d. L'estadistica es basa enel cens dela població ${ }_{i} i s^{\prime} \mathrm{hi}_{i}$ basa the statistics SE base in the census of the population and SE HI bases per imperatiu metodològic. by imperative methodological

'The statistics are based on the population census, and it is based on that bymethodological imperative'

Such cases contain a much less clear locative meaning, and the crucial factor here is that the argument is introduced by a preposition. However, the main prepositions used here have a prototypical locative meaning: en 'in' denotes places, $a$ 'to' denotes goals, per 'through, by' denotes the route of a movement and per $a$ 'in order to' denotes a goal. The preposition amb 'with' (and its opposite, sense 'without') is not directly locative, however. The connection between this last preposition and locations is less clear, but it should be taken into account that with has been argued (Rapoport 2014) to denote a locative central coincidence relation -with a possessive semantic core-. In this sense, saying that someone can count on (with, in Catalan) someone else involves saying that the subject has the person she can count on in her personal space for the relevant time period, and stating that someone has spoken with someone means, at an abstract level, implies that the subject has the person she talks with in her personal space during the talking event. Admittedly, further explanations should be provided about such cases, and in particular about the limits of the place metaphorical extension in contemporary Catalan. However, we hope to have been able to show in this section that treating $h i$ as a place nominal 
avoids the problems that a deictic or case-marking treatment faces, and is compatible with the less locative uses of the expression.

\subsubsection{Arguments licensed via KP vs. arguments lacking KP}

There are two main theories about the nature of case in languages. The first proposal treats case as a property that has to be licensed on a particular type of objects, argument DPs (Chomsky and Lasnik 1977; Vergnaud [1977] 2008; Chomsky 1981). Arguments marked with case are themselves DPs that enter into an agreement relation with a functional category of the appropriate type. In the second type of proposal, case is itself a syntactic projection, KP, which relates DP arguments to predicates, imposing some meaning condition on how they are interpreted (Fillmore 1968; Caha 2009; and with caveats Neeleman and Weerman 1999).

This distinction between case as KP and case as the result of an agreement relation stands next to the descriptive difference between structural and inherent case (Chomsky 1981). Structural case, descriptively, refers to the specific case markings that are highly sensitive to the structural context where they appear, and which are not related to specific thematic interpretations. Nominative and accusative are taken to be prime exponents of this type of case, to the extent that -for instance- in English or Catalan nouns cannot license nominative in their complements, and arguments marked as nominative can have a wide array of thematic interpretations -agent, patient, beneficiary, etc.-. On the other hand, locative and comitative are examples of the second type of case: the thematic interpretation is largely fixed and imposed by the specific case marking they carry, and in contrast the structure where they are embedded does not play a substantial role on how they are marked.

In this article, we assume that inherent case has these properties because it is grammatically expressed through a projection of $\mathrm{KP}(36)$.

[KP K [DP...]]

That KP imposes a particular interpretation to the argument, and allows it to appear in a wider array of configurations without change -because the head $\mathrm{K}$ is responsible of the case assignment, preventing the DP from establishing further formal relations with heads outside the KP constituent-. This follows Neeleman and Weerman (1999) and Caha (2009) approach, in which the presence of KP is justified through different syncretism patterns, the relation to specific thematic meanings, and the extraction and agreement asymmetries identified in Blake (2000), which are interpreted as potential barrier effects of KPs of a certain type (see 
specifically Caha 2009: 25-48). However, we part ways with Caha (2009) in that we do not assume that nominative case is marked with a DP, a point also made by Neeleman and Werman (1999: 62-82). The reasons that these authors give to make this proposal are largely the ones mentioned before: nominative is dependent on the presence of a particular type of assigning head outside its projection, and is not related to a particular thematic interpretation. We distance ourselves from Neeleman and Weerman (1999), though, in that we extend the same arguments to accusatives in languages such as Spanish, English or Catalan. ${ }^{5}$

This, we assume a complete correlation between inherent case - presence of KP and structural case - absence of KP.

(37) a. Inherent case configuration: DP selected by K

b. Structural case configuration: DP without K

This is how we attempt to capture the fact that inherent case is related to a thematic interpretation and is not dependent on the presence of external heads, while structural case has the opposite properties.

Remember the central point made in the introduction that calling two objects 'dative' does not guarantee that they share the same set of properties cross-linguistically. Our claim is that the objects labeled as dative clitics can be, depending on the language or variety, instances of inherent case, or instances of structural case. Specifically, we claim that the 'dative' clitic in nVC is in fact a DP, that is, an object that needs to receive structural case. In other words, it is for all intents and purposes an accusative, whose 'dative' interpretation is due to the presence of a locative embedded in its structure (largely as Martín 2012a, 2012b; claims).

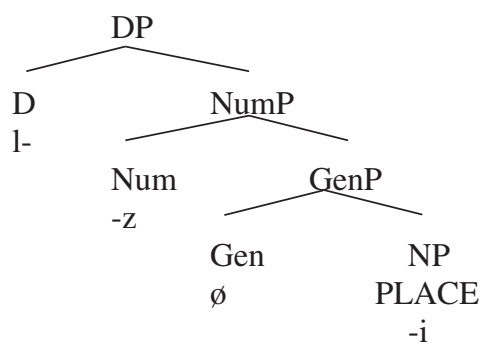

5 Neeleman and Weerman (1999) propose that accusative is headed by a KP because in their treatment nominatives lack morphological marking, while accusatives have it. The argument that KP is always marked morphologically, and vice versa, that case marking involves presence of KP is not used as a criterion in this article. 
In contrast, VC lacks a locative clitic, therefore making the locative noun an unavailable strategy to build the dative meaning. In this variety, we argue, the dative clitic is inherently marked as a KP, and therefore dative and accusative clitics are different in their internal composition.

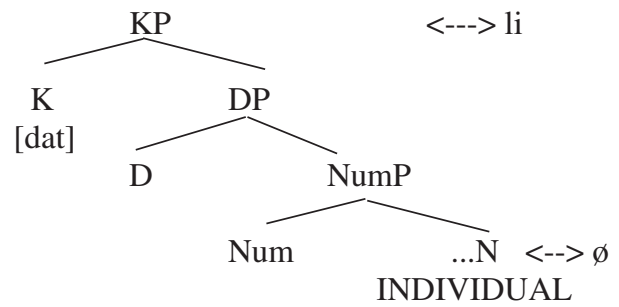

We treat the dative singular in VC as a morphologically undecomposable object where /li/ is the exponent that materialises the set $\mathrm{K}+\mathrm{D}+\mathrm{Num}$, and possibly the gender projections. ${ }^{6}$

In short, given this background our claim is that VC dative clitics are inherently marked as datives, and thus distinguished through KP from accusative clitics. In contrast, both 'dative' and accusative clitics in nVC are bare DPs,

6 In terms of how a single exponent spells out more than one syntactic terminal -synthetic exponence-, we assume Phrasal Spell Out à la Caha (2009), as opposed to other procedures available in the literature (such as Distributed Morphology's Fusion -Halle and Marantz 1993-, Spanning -Ramchand 2008- or head movement -Travis 1984-). In this proposal, an exponent can spell out a set of heads provided that they are contained within the lexical exponent -with the addenda that material previously spelled out, as the $\mathrm{N}$ in the diagram, is ignored in the computation of what counts as a constituent-. This predicts that no single exponent will spell out material distributed across two separate constituents (for instance, a specifier and a complement of the same head, unless the exponent also spells out the head). However, it does not make the opposite prediction, namely that material that forms a single syntactic constituent will be spelled out with only one exponent under any situation. In such situations, this will depend on how many features a particular exponent is associated to in the lexical repertoire; basically, this is an idiosyncratic property of individual exponents. In VC, in our account, it is the case that for instance an exponent like els is associated to the set $\mathrm{K}, \mathrm{D}$, Num and possibly Gender, but in principle this fact is not a consequence of the properties of the syntactic structure, and things could have been different. One anonymous reviewer asks whether we see that there is a direct correlation between the presence of KP and the use of a synthetic exponent in this variety; we have to answer that with the data we have now we cannot make this claim. We can however speculate that containing a place N makes KP unable to project to the extent that the place meaning of $\mathrm{N}$ and the information contained in $\mathrm{K}$ would be to some extent redundant, although, again, the hypothesis has to be checked against detailed study. 
and as such both should receive structural case, which can be labeled 'accusative' in traditional sense. ${ }^{7}$

\subsection{Analysis}

\subsubsection{Accusative clitics: The structure in both VC and nVC}

Let us now see how clitics are decomposed in the two varieties, step by step. We will start with the accusative clitics. We start from the assumption that in both varieties the accusative clitics correspond to the abstract sequence in (40).

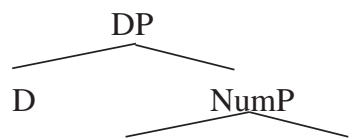

Num

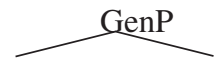

Gen

NP

In what follows, we will assume that these four heads are always present, but can receive an unmarked materialisation with a null exponent if they exhibit the unmarked value for the feature (singular for Num, masculine for Gen). (41) represents the shape of the masculine singular accusative clitic. Given that the accusative can refer to essentially any kind of (individualised) entity, we propose that in the accusative the $\mathrm{N}$ layer is an underspecified nominal that selects from the range of all individuals of discourse.

7 A final analytical distinction is orthogonal to our analysis. As is well-known there are two main approaches to what Romance clitics are. In the first view, clitics are object agreement markers on a par with subject-agreement markers (clitic-as-agreement). This motivates an approach where the ingredients that make up the clitic are the result of the spell out of the heads that compose the clitic area (Sportiche 1996; Halle and Harris 2005), in a sense ObjectAgreement projections of sorts (Kayne 1994). A second approach (clitic-as-argument) is that the clitics are part of the arguments merged internally to the VP as big DPs (Uriagereka 1995; Bleam 1999). On later stages the clitic, as a head inside the big-DP, moves up to a functional layer above the verbal complex. We view this issue as orthogonal to our proposal. Let us explain why. In the first approach, clitics are base generated in a functional area; in the second approach, clitics are generated somewhere else, but have to be licensed in a higher functional area. In both cases, the clitics end up being associated to a set of functional projections, independently of whether they generate there or not. 
(41)

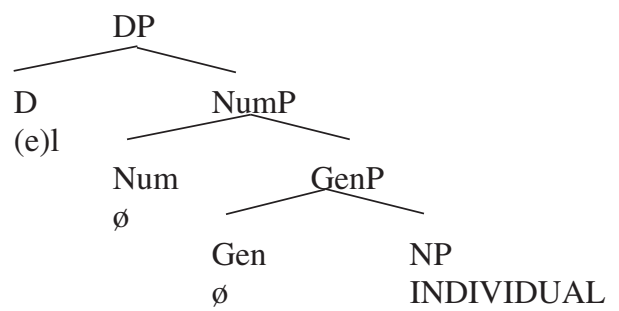

(42) shows how the same structure can give account of the feminine and plural forms for masculine and feminine; one just needs to assume head movement of Gen to Num to account for the relative ordering feminine + plural in one form.

(42)

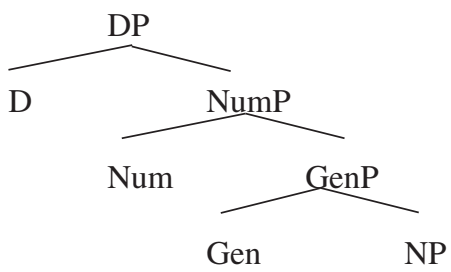
a. (e)l s $\varnothing$
IND
m.pl
b. $1 \quad \varnothing \quad \mathrm{a}$
IND
f.sg
c. $\quad 1 \quad \mathrm{e}_{\mathrm{i}}+\mathrm{s} \quad \mathrm{t}_{\mathrm{i}}$
IND
f.pl

In the case of the neuter, remember that neuter forms are only found in pronouns in Catalan, where they are used to refer to propositions, predicates and other abstract entities. For this reason, they do not take gender or number inflection. All this leads us to propose, provisionally, that the neuter ho spells out the $\mathrm{N}$ layer, as the materialisation of a noun that defines the range of the pronoun as not covering individuals but abstract units as propositions and predicates. In $\S 5.1$. we will refine the structure of the neuter, given its behaviour in combination with the locative. 
(43) Neuter $h o / u /{ }^{8}$ (to be revised)

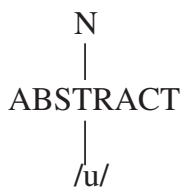

\subsubsection{Dative clitics in each variety}

Let us now move to the dative, where the varieties differ. Starting from nVC, remember that here the 'dative' contains the locative clitic, which we have motivated should be analysed as a N corresponding to PLACE that restricts the reference of the pronoun to regions in space. ${ }^{9}$ (44) represents the decomposition in singular (44a) and plural (44b).

(44)

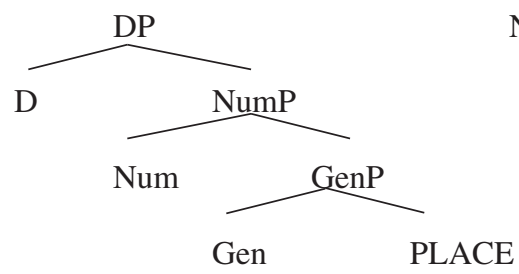

Non Valencian Catalan datives

8 Depending on the dialectal area, ho is pronounced with a high back vowel or with a mid back vowel.

9 The situation where dative pronouns contain -or are identical to- locative clitics is crosslinguistically well-attested (see, for instance, Latin; Martín 2012a). Paduan (Kayne 2008) shows complete identity between third person datives and locatives (we thank an anonymous reviewer for pointing us towards this pattern of data).

(i) Ghe dago il libro

Dat give.1sg the book

'I give him/her/them the book'

(ii) Ghe meto il libro

loc put.1s the book

'I give him/her/them the book'

Note, however, that we do not claim that any language that has a locative clitic available is forced to use it to build the 'dative' clitics. 
We have taken the assumption of representing GenP in the stucture, and marked as zero. It is, alternatively, possible that GenP is not present, if PLACE is not specified for gender, as a neuter of sorts. Alternatively, PLACE can be taken to be a masculine noun which, as in other cases, takes $\varnothing$ marking for gender. Either way (if PLACE only has one gender, which happens to be masculine, or if PLACE lacks gender) this captures that datives lack the gender motion that accusatives have in $\mathrm{nVC}$.

The most important property of (44) is that it lacks a KP; therefore, this clitic is structurally indistinguishable from the accusative clitic in (42).

In contrast, the dative in Valencian Catalan, where there is no locative clitic, has to receive a completely different analysis. We propose that in this variety the dative clitic $l i$ is marked with dative-case through a KP and consists minimally of a case-marked determiner. The INDIVIDUAL denoting $\mathrm{N}$ is spelled out as zero.

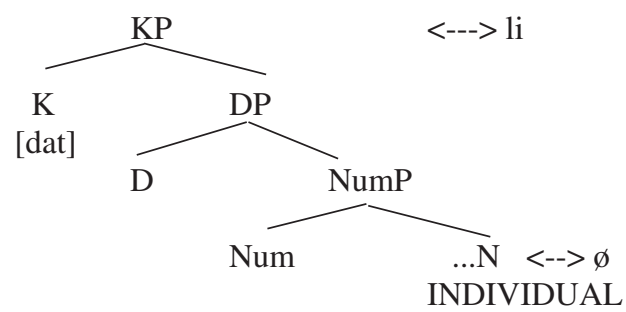

Crucially, the absence of a / i/ form in the clitic system and the absence of / $i$ / marking in the dative plural forces the speaker of this variety to adopt a synthetic analysis of the dative clitic, as a morphologically undecomposable form where the whole structure is spelled out with a single exponent /li/, which is distinguished from the other clitics by carrying a KP defined as dative.

Following the proposal that the plural dative form in VC is equally undecomposed (remember the contrast between 11 and 12), the following diagram reflects how the structure is matched to the relevant exponents.

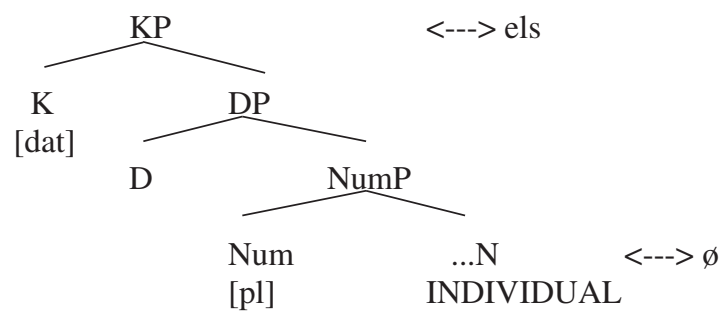


In this approach, els spells out the complex D + Num[plural] when marked for dative case. Alternatively -and as far as we can see it, nothing in the data we have at the moment favours one of the two alternatives- it could be proposed that the /z/ is segmented to mark plural, and the form /1/ (with the epenthetic $e$ ) is an allomorph of the dative determiner used in the context of plural.

(47)

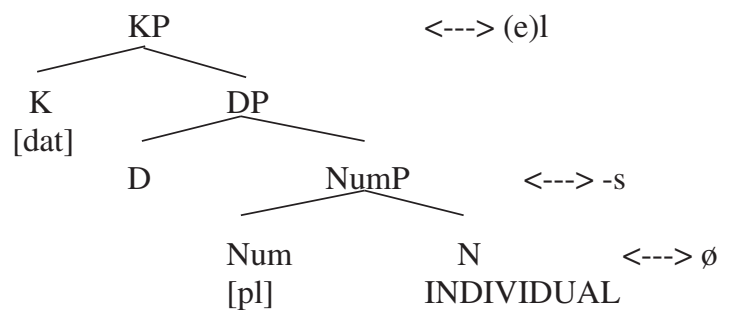

(48) $[\mathrm{K}[\mathrm{D}]]<->(\mathrm{e}) \mathrm{l}-/{ }_{-}-\mathrm{S}$

Leaving this complication aside, the crucial claim is that VC dative clitics are not built over a locative N, but DPs marked as dative through $\mathrm{KP}$, and therefore distinct from accusative clitics.

\subsubsection{Clitic combinations with two sequences}

We are now in a position to motivate that in VC it is possible to spell out a clitic sequence licensing each aspect of the meaning of the clitic without any surface impoverishment. Our claim is that because the two clitics are distinguished by case marking in this variety, it is possible for this language to license each clitic in a distinct series of heads within the clitic area, as schematised in (49). 


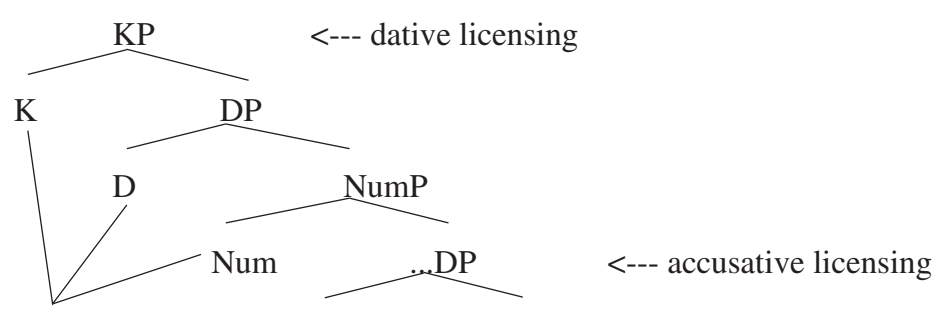

(e)ls

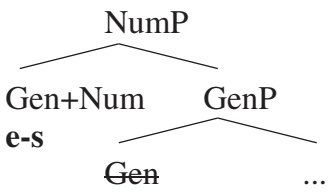

The key of our analysis is that, because each clitic receives a different case marking, the clitic area can treat them as different objects and use distinct sets of projections to license them separately. In consequence, the gender, number and definiteness information is duplicated in the clitic cluster.

\subsubsection{Clitic combinations with one sequence: $n V C$}

In contrast, in nVC the dative is categorically identical to the accusative, for all intents and purposes. In other words: as opposed to VC, where the dative clitic is a KP marked with dative as inherent case, the object that has received the name of 'dative clitic' in $\mathrm{nVC}$ is the combination of a locative $\mathrm{N}$ and the structure associated to the determiner. Given that neither the 'dative' clitic nor the accusative clitic are marked by KP, they are forced to share the same licensing space in the clitic area. To put it in clearer terms: $\mathrm{nVC}$, for 3rd person clitics, only has one D, one Num, one Gen and one $\mathrm{N}$ to license the argument.

(50)

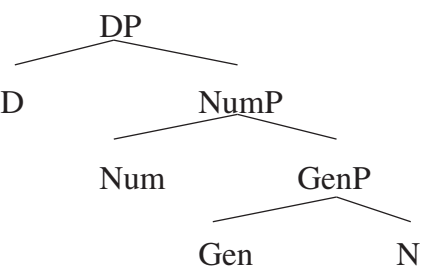

For this reason the surface forms in the clitic combinations become reduced to what essentially is one single clitic. The details of how the licensing of both clitics 
takes place depend on the assumptions about whether clitics are argument or agreement markers (see footnote 7), but here we will present it in terms of agreement. The idea is that in a situation where there are two arguments, an accusative and a 'dative', the only D head available for 3rd person pronouns in $\mathrm{nVC}$ will act as a multiple probe that checks the features of the two D layers involved in the two arguments. Similarly, Num will probe the number information of both arguments, and the same is the case for gender (see $\S 5.3$ for more facts about this head) and $\mathrm{N}$. In all these cases, the morphological piece introduced reflects the most marked value for each feature -when the information of the two arguments is different-. For instance, if one argument is singular and the other is plural, irrespective of which one of the two (accusative or 'dative') carries plural, Num in the 3rd person area will check the two values, and the resulting clitic be spelled out as plural, as the more marked of the two values.

For this reason, only two situations have to be distinguished. In the first one both arguments are singular.

(51)

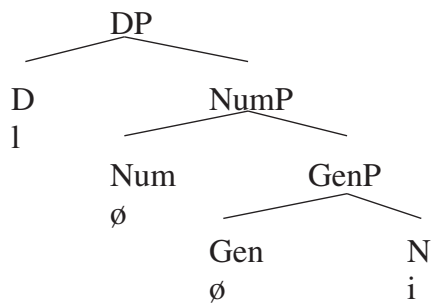

Here, the $\mathrm{N}$ layer is filled by the PLACE nominal. This derives directly from the Elsewhere Principle that favours the spell out of the more specific forms over more underspecified forms. Remember that in the accusative clitics we have associated the $\mathrm{N}$ layer to an underspecified nominal that selects any kind of individual in discourse (52a). In contrast, the /i/ exponent is a locative nominal that selects a very specific subset of individuals, regions in space (52b).
a. Nindividual $\longleftrightarrow-\varnothing$
b. Nplace $\longleftrightarrow->$ i

In competition, then, the locative $\mathrm{N}$ will win, and be introduced in (51). That the $\mathrm{N}$ layer is filled by the locative $\mathrm{N}$ imposes null marking for gender, so Gen is $\varnothing$ because Nplace is only licensed below a null gender marking. Number is singular for both nouns, so the marking in Num is also $\varnothing$, and D is filled. 
Consider now the second situation in nVC, which is identical to (51) only that now one (or both) arguments are plural. This makes Num to be spelled out as /s/.

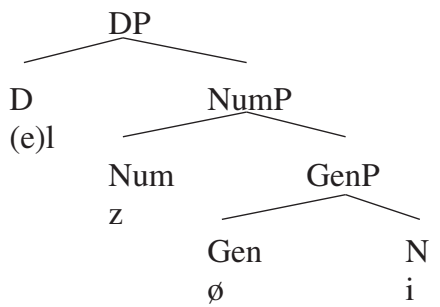

To be very explicit: the problem with $\mathrm{nVC}$ is that in this variety the clitic area only has space for a single clitic, because both 'datives' and accusatives are the same type of object. Thus, within the only sequence D-Num-Gen-N the two arguments have to check their properties, and there is only place for one marking per head. ${ }^{10}$ This makes the maximal size of the overt material that can be present in a third person clitic sequence in nVC restricted to:
(a) One $\mathrm{N}$, here PLACE
(b) One gender (determined by PLACE)
(c) One number
(d) One D

\subsubsection{Valencian Catalan, second variety}

The idea is that if the clitic system distinguishes dative and accusatives through case marking, the clitic area can be duplicated in order to host the dative in one

10 As an anonymous reviewer points out, an interesting point of comparison would be the variety of Sardinian mentioned in Kayne (2008) where the incompatibility between the two 3rd person clitics is resolved not by altering the dative, but by substituting the accusative with a locative clitic:

(i) Narra-bí- lis

Tell cl:loc cl:dat.3pl

'Tell them (about it)'

Although addressing this case with some guarantee of success requires a careful and detailed research on this variety that we have not conducted, we can make a few remarks about this case. One of them is that the morphological make-up of the dative does not include the locative clitic, which already tells us that this type of dative is different from the nVC studied in this article. One can speculate that what clashes in this variety is the type of $\mathrm{N}$ contained inside the dative and accusative clitics, triggering a substitution of the individual $\mathrm{N}$ layer by a place $\mathrm{N}$ layer, but at this point the reasons for this clash are very unclear to us, and leave this case for further research. 
sequence and the accusative in another sequence. The nVC varieties that do not define the dative with a distinct case are therefore forced to use one single sequence of heads for both arguments, but the principle is not a biconditional. Nothing in the system, as we have stated it, forces that if both clitics are marked with distinct cases there should be two distinct series of heads to license each one of them. In fact, we claim that VC2 illustrates a situation where the clitics are marked with distinct cases but they compete for licensing in the same set of heads.

The proposal is that in this second variety of Valencian the clitic area is not fully duplicated for third person clitics. If there are two third person clitics, then, as there is only one clitic area to license case, the dative clitic -which is marked for case- takes preference and the accusative clitic has to fit in the remaining heads. In this variety, then, rather than talking about 'dative' and 'accusative' licensing it is more appropriate to talk about 'internal argument case licensing'.

The surface difference with nVC follows from the fact that VC lacks a locative clitic, which translates as the claim that the $\mathrm{N}$ layer is not occupied by PLACE and is then available for the accusative argument. Note that, as follows from the entries proposed in $\S 3.1$., /o/ corresponds to the spell out of an $\mathrm{N}$ layer deprived of gender and number projections. In other words: although morphosyntactically there is no neuter argument, in this variety the exponent for the neuter clitic emerges in these conditions because the $\mathrm{N}$ layer is available for the accusative argument, and /o/ happens to spell out this layer.

Starting here, two situations have to be distinguished, illustrating the primacy of the dative-marked argument here. In the first one the dative-marked /li/ does not spell out number, which is available for the accusative argument, which controls whether Num is spelled out as $\varnothing$ or as -s.

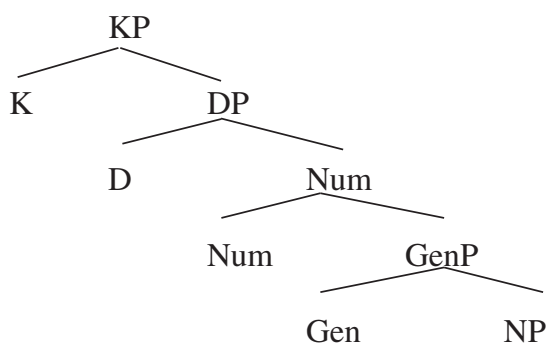
a. $\quad$ li $\varnothing \quad \varnothing$
ho ([liw]) singular dat + singular acc
b. li ho+s $\varnothing$
he ([liws]) singular dat + plural acc 
In the second situation, the dative also consumes plural; in such cases, irrespective of whether the accusative is singular or plural, the resulting form is the same:

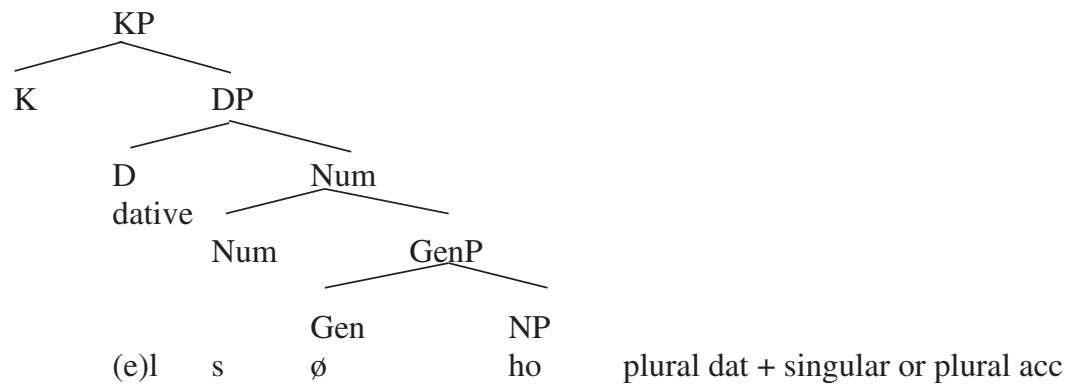

\section{Extensions}

In this section we will extend the approach to other cases within the varieties discussed.

\subsection{Refining the structure of the neuter}

In this section we will refine the proposal made about the internal morphological make-up of the neuter pronoun in Catalan under the light of the result obtained when a locative and a neuter clitic co-occur in the same sentence. As can be seen in (56a), in nVC it is possible to find verbs that select both a locative and a neuter accusative. In such cases, the simultaneous cliticisation of both the neuter and the locative produce what on the surface looks like a dative singular masculine form (56d):

(56) a. Porta això que t'he preparat a la taula bring that that you.dat-have prepared to the table 'Bring what I have made for you to the table'

b. Porta-ho a la taula. bring-it to the table

c. Porta-hi això que t'he preparat. bring-there that that you.dat-have prepared 'Bring there what I have made for you' 
d. Porta-l'hi [li].

bring-it.there

'Bring it there'

How is this captured in our analysis? In order to explain it, we will revisit the structure proposed for the neuter and argue that it does not consist only of an Nlayer, but actually contains a DP layer as well:

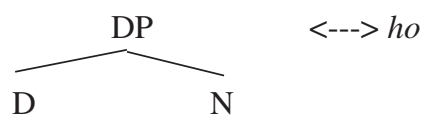

ABSTRACT

The reason is that the neuter refers to an abstract object, which in the decomposition must involve two distinct layers: an $\mathrm{N}$ layer which restricts the range of entities to which it can refer to abstract individuals (propositions, predicates, etc.), and a D layer that allows it to be referential. This is what makes it possible for the neuter to refer back to such entities:

a. Son metges, però no ho volen dir.

Are.3pl doctors, but not it want.3pl say

'They are doctors, but they do not want to say it [='that they are doctors']

b. La que està parlant sembla la Maria. -Sí que ho és. that who is talking seems the Maria yes that it is

'The one talking seems Maria. -Yes, it [='that she is Maria'] is true'

In contrast, the locative does not contain a D layer. If (57) is the internal structure of the neuter, then we have the following lexical entries for the neuter, the D component of the clitics and the locative noun:

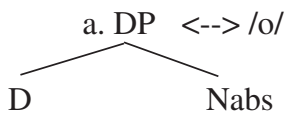<smiles>[N+]#[N+]</smiles><smiles>[2H]I</smiles>

That is: the sum of D and an abstract N (59a) for the neuter, /i/ as a spell out for $\mathrm{N}$ when it has a PLACE meaning, and /1/ as the spell out of $\mathrm{D}$ alone. Now we are in a condition to explain why the addition of the locative and the neuter produces a form that is surface-identical to the dative singular. Assume, as before, a single clitic area for $\mathrm{nVC}$, where - given that here we combine a locative and a neuter- we have the structure in (60), where the gender and number projections are not needed for either clitic: 
(60)

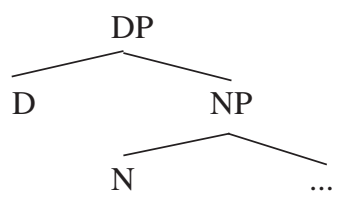

The N-layer becomes occupied by the PLACE element, and this is spelled out as /i/. Again, this is an instance of the Elsewhere Principle, whereby the semantic information associated to the place nominal is more specific than the one associated to the abstract nominal. The abstract nominal picks out from the domain of individuals that lack gender and number, but the locative clitic picks out from the domain of individuals denoting place, which also lack gender and number.

(61) a. Nplace $<->$ i

b. Nabs $\longleftrightarrow->0$

c. Nind $\longleftrightarrow->\emptyset$

Filling $\mathrm{N}$ with the locative leaves only $\mathrm{D}$ to spell out: the /1/ element and the neuter are both candidates to spell out $\mathrm{D}$. Given that $\mathrm{N}$ is already taken by the locative element, $/ 1 /$ is prefered in this context over the neuter, because it spells out the remaining head without additional material. This produces, correctly, the form /li/:

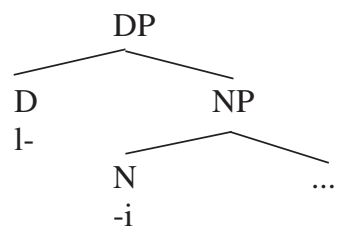

Similarly, this correctly predicts that the combination of dative and neuter will produce a dative in the same varieties $(l i+h o=l i$; $e l z i+h o=e l z i)$.

\subsection{Dative and locative}

When both the dative and the locative co-occur, we obtain one single dative:
a. Posa-li
/ lzi diners a
compte corrent. put-\{him/her\} / them money in-the account current 'Put $\{$ him / her / them $\}$ money in the bank account'. 
b. Posa-li / lzi diners.

Put- $\{$ him/her $\}$ / them money

'Put $\{$ him / her / them $\}$ money there.

This is straightforwardly expected in our approach: as the dative contains the locative, the $\mathrm{N}$ layer is filled by Nplace, and the rest of the projections are available for licensing the rest of features of the dative clitic, resulting in surface identity of the sequence with a single dative pronoun.

\subsection{Further variation in nVC: Gender motion in clitic sequences}

Remember the structure proposed in our analysis for $\mathrm{nVC}$ sequences where one of the elements is plural:

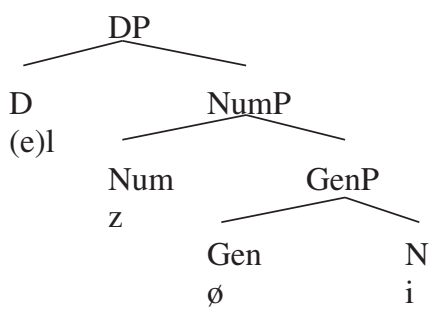

In (64), we argued, there is no gender motion because Gender is controlled by the PLACE N /i/. However, nothing in our theory forces this: it could also happen that Gen is controlled through agreement or movement by the gender of the accusative argument. And this in fact happens in nVC from Camp de Tarragona :

(65) a. Li vaig donar les targetes $->$ les hi vaig donar ahir. him I.go give the cards them.f loc I.go give yesterda 'I gave him the cards, I gave them to him yesterday'

b. Li vaig donar els llibres $->$ els hi vaig donar ahir. him I.go give the books them.m loc I.go give yesterda 'I have him the books, I gave them to him yesterday'

This is what we expect if in this variety the fact that /i/ fills $\mathrm{N}$ inside the clitic cluster does not force that GenP becomes inactive, and Gen can be either masculine or feminine depending on the properties of the accusative argument.

The microparametric difference between this variety and the other $\mathrm{nVC}$ varieties, where Gen becomes $\emptyset$ in the presence of /i/ can be easily represented 
as a constraint that applies to the exponents involved. In most varieties of $\mathrm{nVC}$, gender is null in the presence of /i/:

Gen $<----->\varnothing / \ldots \mathrm{N} / \mathrm{i} /$

The variety of Camp de Tarragona, in contrast, lacks this constraint.

\subsection{A note on personal pronouns}

Another well-known clitic cluster restriction is the Person Case Constraint (cf. Perlmutter 1971; Bonet 1991; Adger and Harbour 2007, Anagnostopoulou 2003; among many others). In its strong form, the restriction bans a combination of a 3rd person dative clitic and a 1st or 2nd person accusative clitic (67a), which in nVC is solved by turning the dative into a locative pronoun (67b; cf. Bonet 2002: 950-952). This solution is, obviously, not possible in VC, where there is no locative.
a. * Al director me li va recomanar el senyor Bofill. dat-the director me.acc him.dat aor recommend the mister Bofill
b. Al director $\mathrm{m}$ ' hi va recomanar el senyor Bofill. dat-the director me.acc loc aor recommend the mister Bofill 'To the director, Mister Bofill recommended me'

Even though this article concentrates on 3rd person clitic combinations, here we want to make explicit how we see that the general type of analysis argued for in this article extends to such cases -obviously, without being to develop a full analysis here-. An anonymous reviewer points out to us that there are two puzzling facts about personal pronouns in Catalan varieties that are relevant for our type of analysis. The first one is that personal pronouns never morphologically differentiate between dative and accusative, even in VC:
a. me
me, accusative and dative
b. te
c. ens
you.sg, accusative and dative
us, accusative and dative
d. us
you.pl, accusative and dative

The second one is that personal pronouns and datives show certain similarities, among them (i) the absence of gender distinctions and (ii) that under certain 
conditions they both combine with the preposition a 'to', in what seems to be an instance of differential object marking.
a. ${ }^{\star}(\mathrm{A})$ la Maria li dic sempre la veritat DOM the Mary dat.3s say.1sg the truth 'To Maria, I tell the truth'
b. ${ }^{\star}(\mathrm{A}) \mathrm{mi}$ em veus cada dia. DOM me 1s say.2sg each day 'You see me every day'

In what follows, we will sketch our general approach to explaining these similarities, and show how we believe that they explain the strong PCC effect noted above. Our starting point is Kayne's (2010) proposal that, within the clitic area, the personal pronouns are licensed in a region above third person pronouns -both dative and accusative, in the case of VC-.

$$
\begin{aligned}
& \text { (70) }[\text { es }[\mathrm{me} / \mathrm{te} \text { [3rd person ...]]] } \\
& \text { reflexive me / you }
\end{aligned}
$$

This already explains why personal pronouns do not differentiate between accusative and dative even in varieties that differentiate them through case marking: both are licensed within an area that is above the regions where the distinction is relevant.

With respect to why a PCC effect is triggered and why datives and personal pronouns share properties, here is our general approach. As Adger and Harbour (2007) extensively argue, there is evidence that datives need to be related in their interpretation to animacy properties, taken in a general sense which makes the feature be interpreted as a form of affectedness when the entity is conceptually inanimate. This being a semantic fact, we take it to apply to both fake datives without KP and datives carrying KP. Due to the necessity to be interpreted in this way, datives will have to undergo two separate licensing operations: in the first one, they can share the area with other 3rd person pronouns -if the variety does not split between dative and accusative clitics-, triggering the type of clash we have concentrated on in this article. In the second licensing operation, which satisfies animacy, they compete with personal pronouns in the area above 3rd person clitics. This explains the shared properties between the two types of clitics, and also the existence of PCC effects. To be as explicit as we can at this point, we assume a movement operation of the constituents in the 
(dative) 3rd person area to the personal pronoun area above it, as in (71) -where we represent each area as one single head, for the sake of simplicity-.

(71) [PersonP [1-i] Person $^{0}$ [3rdP [1-i] $\left.\left.3 \operatorname{rd}^{0} \ldots . ..\right]\right]$

When a personal pronoun is present, that area is already occupied, triggering a similar competition as the one we saw: the exponents me, te, ens, us spell out the D and Num heads in that area, making number and D marking on the dative unavailable; only the place $\mathrm{N}$ is left for that clitic, making it sound on the surface as a single locative hi. Obviously, much more should be said about this analysis, ${ }^{11}$ but we hope to have given the reader at least an idea of how our analysis would be extended to cover also these cases.

\section{Final conclusions}

In this article we have argued for an approach to clitic clusters where the (im) possible third person sequences depend on the internal composition of the clitic traditionally treated as a dative. Specifically, we have argued that it matters for the sequence whether the traditional dative is a real dative-marked pronoun or a DP containing a locative noun. If the accusative and the 'dative' are not distinguished by case, the clitic area must license them in the same set of heads, with the result that there is surface impoverishment of the cluster. In contrast, when each clitic is defined differently, it is possible in the language to license each one in a different set of heads, although, as VC2 showed, this depends on the language independently splitting the clitic area in separate regions for accusative and dative.

Crucially, note that our proposal captures the same set of facts as the syntactic distinctiveness approach (cf. Richards 2010) without the need to stipulate Distinctiveness as an additional principle in syntax. The Distinctiveness Approach makes the claim that two constituents with the same label cannot appear together within the same syntactic domain. In our approach, the effect of Distinctiveness is recast as standard competition for licensing by the same head, making it redundant as a separate principle. In this sense, we follow the same general view as Ormazábal and Romero (2013), who see case disimilation

11 For instance, varieties where only a weak PCC effect is observed and 1st and 2nd person pronouns can combine with each other would presumably involve a splitting of the personal pronoun area in two separate regions, one for 1st person and another one above it for 2nd person. 
(absence of Differential Object Marking) in the presence of a dative-marked argument as a standard case of competition for case licensing by the same head.

(72) a. *Entregué a los prisioneros a María.

b. Entregué los prisioneros a María.

Our approach argues also against using morphological OCP effects to analyse clitic cluster restrictions, making the postsyntactic mechanisms of impoverishment unnecessary. Admittedly, we have not discussed here all the wealth of data that Bonet and others (such as Pescarini 2002, 2011) have introduced in the theoretical debate. In spite of the empirical coverage of our proposal, however, we believe that our contribution can be taken as a promisory note for a purely syntactic account of clitic clusters across languages, but time will tell whether the rest of patterns can receive plausible accounts in our general proposal, or morphological operations will be needed at some point.

Acknowledgements: We are grateful to two anonymous reviewers, Anna Bartra, Víctor Acedo-Matellán, Jaume Mateu, Carme Picallo, Gillian Ramchand, Peter Svenonius, and Tarald Taraldsen for comments and suggestions to previous versions of this article. All disclaimers apply.

\section{References}

Abels, K. 2003. Successive cyclicity, anti-locality and adposition stranding. PhD dissertation, University of Connecticut.

Adger, D. \& D. Harbour. 2007. Syntax and syncretism of the person case constraint. Syntax 10. 2-37.

Anagnostopoulou, E. 2003. The syntax of ditransitives: Evidence from clitics. Berlin: Mouton de Gruyter.

Bayer, J. 2004. Non-nominative subjects in comparison. In P. Bhashakarao \& K. V. Subbarao (eds.), Non nominative subjects, 31-58. Amsterdam: John Benjamins.

Blake, B. J. 2000. Case. Cambridge: Cambridge University Press.

Bleam, T. 1999. Leista Spanish and the syntax of clitic doubling. PhD dissertation, University of Delaware.

Boeckx, C. \& J. Martín. 2013. El clític datiu és més que un clític. Lleida: Pagès editors.

Bonet, E. 1991. Morphology after syntax. PhD dissertation, MIT.

Bonet, E. 1993. 3rd person pronominal clitics in dialects of Catalan. Catalan Working Papers in Linguistics 3. 85-111.

Bonet, E. 1995. Feature structure of Romance clitics. Natural Language and Linguistic Theory 13(4). 607-647. 
Bonet, E. 2002. Cliticització. In Joan Solà et alii (ed.), Gramàtica del català contemporani, v.l, 933-989. Barcelona: Empúries.

Caha, P. 2009. The nanosyntax of case. Ph. D. thesis, University of Troms $\varnothing$.

Chomsky, N. 1965. Aspects of the theory of syntax. Cambridge (Mass.): MIT Press.

Chomsky, N. 1981. Lectures on government and binding. Berlin: De Gruyter.

Chomsky, N. 2000. Minimalist inquiries: The framework. In R. Martin et al. (ed.), Step by step, 89-115. Cambridge (Mass.): MIT.

Chomsky, N. 2001. Derivation by phase. In M. Kenstowicz (ed.), Ken Hale: A life in language, 1-52. Cambridge (Mass.): MIT Press.

Chomsky, N. 2005. Three factors in language design. Linguistic Inquiry 36(1). 1-22.

Chomsky, N. \& H. Lasnik. 1977. Filters and control. Linguistic Inquiry 8. 425-504.

Cinque, G. 2005. Deriving Greenberg's Universal 20 and its exceptions. Linguistic Inquiry 48. 181-193.

Cuervo, M. C. 2003. Datives at large. Ph.D. dissertation, MIT.

Déchaine, R.-M. \& M. Wiltschko. 2002. Decomposing pronouns. Linguistic Inquiry 33. 409-442.

Fillmore, C. J. 1968. The case for case. In E. Bach \& R. T. Harms (eds.), Universals in linguistic theory, 1-88. New York: Holt, Rinehart, and Winston.

Gísli Jónsson, J. 2012. Dative vs. accusative and the nature of inherent case. In B. Fernández \& R. Etxepare (eds.), Variation in datives: A microparametric perspective. Oxford: Oxford University Press.

Hale, K. \& S. J. Keyser. 2002. Prolegomenon to a theory of argument structure. Cambridge (Mass.): MIT Press.

Halle, M. \& J. W. Harris. 2005. Unexpected plural inflections in Spanish: Reduplication and metathesis. Linguistic Inquiry 36. 195-222.

Halle, M. \& A. Marantz. 1993. Distributed Morphology and the pieces of inflection. In K. Hale \& S. J. Keyser (eds.), The view from Building 20, 111-176. Cambridge (Mass.): MIT Press.

IEC. Institut d'Estudis Catalans. 2016. Gramàtica de la llengua catalana. Barcelona: IEC.

Kayne, R. 1994. The antisymmetry of syntax. Cambridge (Mass.): MIT Press.

Kayne, R. 2005. Movement and silence. Oxford: Oxford University Press.

Kayne, R. 2008. Expletives, datives, and the tension between morphology and syntax. In T. Biberauer (ed.), The limits of syntactic variation, 175-217. Amsterdam: John Benjamins.

Kayne, R. 2010. Toward a syntactic reinterpretation of Harris and Halle (2005). In B. KampersManhe, R. Bok-Bennema \& B. Hollebrandse (eds.), Romance languages and linguistic theory 2008, 145-170. Amsterdam and Philadelphia: John Benjamins.

Kayne, R. \& J.-Y. Pollock. 2010. Notes on French and English demonstratives. In J. W. Zwart \& M. de Vries (eds.), Structure preserved, 215-228. Amsterdam: John Benjamins.

Leu, T. 2015. The architecture of determiners. Oxford: Oxford University Press.

Martín, F. J. 2012a. Deconstructing Catalan object clitics. Ph. D. dissertation, New York University.

Martín, F.J. 2012b. The internal structure of dative cltics. Proceedings of the ConSOLE XVII. 231-252. http://www.sole.leidenuniv.nl.

Mascaró, J. 1986. Cliticització. In J. Mascaró (ed.), Morfologia, 123-141. Barcelona: Enciclopèdia Catalana.

Moore, J. \& D. Perlmutter. 2000. What does it take to be a dative subject?. Natural Language and Linguistic Theory 18. 373-416.

Næss, Å. 2009. Varieties of dative. In A. Spencer \& A. Malchukov (eds.), The Oxford Handbook of Case, 572-581. Oxford: Oxford University Press. 
Neeleman, A. \& F. Weerman. 1999. Flexible syntax. Dordrecht: Kluwer.

Nevins, A. 2012. Haplological dissimilation at distinct stages of exponence. In J. Trommer (ed.), The morphology and phonology of exponence, 84-117. Oxford: Oxford University Press.

Ormazábal, J. \& J. Romero. 2013. Object agreement, clitics and dialectal variation. Probus 25(2). 301-344.

Panagiotidis, P. 2002. Pronouns, clitics and empty nouns. Amsterdam: John Benjamins.

Perlmutter, D. 1971. Deep and surface structure constraints in syntax. New York: Holt, Rinehart and Winston.

Pescarini, D. 2002. Clitic clusters and morphological repairs. Evidence from Italian, Spanish and Barceloní. Studi linguistici e filologici 2 (2).

Pescarini, D. 2011. Mapping Romance clitic sequences. Quaderni di lavoro ASIt 12. 1-29.

Picallo, C. 2006. Some notes on grammatical gender and l-pronouns. In K. von Heusinger et al. (ed.), Specificity and the evolution/emergence of nominal determination systems in Romance, 107-121. Konstanz: University of Konstanz.

Ramchand, G. 2008. First phase syntax. Cambridge: Cambridge University Press.

Ramchand, G. \& P. Svenonius. 2014. Deriving the functional hierarchy. Language Sciences 46. 152-174.

Rapoport, T. 2014. Central coincidence: The preposition with. Faits de langues 44. 159-173.

Richards, N. 2010. Uttering trees. Cambridge (Mass.): MIT.

Rigau, G. 1978. 'Hi’ datiu inanimat. Els Marges 12. 99-102.

Rigau, G. 1982. Inanimate indirect object in Catalan. Linguistic Inquiry 13(1). 146-150.

Sportiche, D. 1996. Clitic constructions. In J. Rooryck \& L. Zaring (eds.), Phrase structure and the lexicon. Dordrecht: Kluwer.

Stassen, L. 1997. Intransitive predication. Oxford: Oxford University Press.

Todolí, J. 1992. Variants dels pronoms febles de tercera persona al País Valencià: Regles fonotàctiques i morfològiques subjacents. Zeitschrift für Katalanistik: Revista d'Estudis catalans 5. 137-160. Frankfurt am Main.

Travis, L. M. 1984. Parameters and effects of word order variation. Ph. D. thesis, MIT.

Uriagereka, J. 1995. Aspects of the syntax of clitic placement in Western Romance. Linguistic Inquiry 26. 79-124.

Vergnaud, J.-R. [1977] 2008. Letter to Noam Chomsky and Howard Lasnik on "Filters and control”. In R. Freidin, C. P. Otero \& M. L. Zubizarreta (eds.), Foundational issues in linguistic theory: Essays in honor of Jean-Roger Vergnaud, 3-15. Cambridge (Mass.): MIT Press.

Viaplana, J. 1980. Algunes consideracions sobre les formes clítiques del barceloní. Anuario De Filología 6. 459-483. Barcelona.

Walkow, M. 2011. Person effects and the representation of third person. An argument from Barceloní Catalan. In J. Berns, H. Jacobs \& T. Scheer (eds.), Romance Languages and Linguistic Theory 2009. Selected papers from 'Going Romance' Nice 2009, 343-361. Amsterdam: John Benjamins.

Wiltschko, M. 2014. The universal structure of categories. Cambridge: Cambridge University Press.

Woolford, E. 2006. Lexical case, inherent case and argument structure. Linguistic Inquiry 37. 11-130.

Zaenen, A., J. Maling \& H. Thráinsson. 1986. Case and grammatical function. The Icelandic Passive. Natural Language and Linguistic Theory 3. 441-483. 